\title{
Individualized initiation of statin therapy determined by baseline LDL-C:Are you more likely to achieve goal LDL-C?
}

This article was published in the following Dove Press journal:

Risk Management and Healthcare Policy

19 December 2009

Number of times this article has been viewed

\author{
James R Clem' \\ Joe D Strain² \\ Debra K Farver ${ }^{3}$ \\ 'South Dakota State University \\ College of Pharmacy Sioux Falls, \\ South Dakota, USA; ${ }^{2}$ South Dakota \\ State University College of Pharmacy, \\ Rapid City Regional Hospital, Rapid \\ City, South Dakota, USA; ${ }^{3}$ South \\ Dakota State University College of \\ Pharmacy, Yankton, South Dakota, USA
}

Correspondence: James Clem Professor of Pharmacy Practice and Department Head, South Dakota State, University College of Pharmacy, 480 I North Career Avenue, Sioux Falls, SD 57।07, USA

Tel + I 605-367-5637

Fax + | | -605-782-3218

Email james.clem@sdstate.edu

\begin{abstract}
Cardiovascular disease remains the leading cause of death in the world. A significant amount of clinical data are available to demonstrate the positive influence that 3-hydroxy-3methylglutaryl coenzyme A reductase inhibitor (statin) therapy has on slowing the progression of cardiovascular disease and improving clinical outcomes. Achieving the treatment goals for cholesterol in cardiovascular disease continues to present challenges. Recent clinical trial information is available assessing the use of more aggressive initial doses of statin therapy based on initial low-density lipoprotein cholesterol (LDL-C) measurements in an attempt to reach treatment goals sooner. Six clinical trials assessed low-, moderate- and high-risk individuals as well as those with type 2 diabetes mellitus to determine if this treatment approach is both safe and effective. The studies concluded that initial dosing of statin therapy determined by a baseline LDL-C measurement demonstrates good achievement in reaching treatment goals and does not result in a higher rate of adverse effects.
\end{abstract}

Keywords: LDL-C, statin therapy, treatment goals

\section{Introduction}

Cardiovascular disease continues to be the leading cause of death worldwide and coronary heart disease (CHD) accounted for approximately 7.6 million deaths in $2005 .{ }^{1}$ Research has revealed that increased low-density lipoprotein cholesterol (LDL-C) significantly contributes to this disease process. ${ }^{2}$ Based on these data the National Cholesterol Education Program (NCEP) and the Joint European Societies emphasize LDL-C lowering as a critical step in the management of CHD. ${ }^{2,3}$ Recommendations state goal LDL-C level is $<100 \mathrm{mg} / \mathrm{dL}$ for patients with a history of CHD and for patients having what is considered a risk equivalent to $\mathrm{CHD} .{ }^{2,3}$ More recent data suggest that although there is strong evidence for a goal LDL-C of $<100 \mathrm{mg} / \mathrm{dL}$ practitioners should consider a goal of $<70 \mathrm{mg} / \mathrm{dL}$ for the highest-risk patients. ${ }^{4,5}$ Diabetes mellitus is identified as one of the risk equivalents to CHD and the American Diabetes Association endorses the goal LDL-C level of $<100 \mathrm{mg} / \mathrm{dL}$ for diabetes patients and further states that a goal of $<70 \mathrm{mg} / \mathrm{dL}$ should be considered for diabetes patients with CHD. ${ }^{2,3,6}$

LDL-C lowering is frequently achieved through the use of 3-hydroxy-3methylglutaryl coenzyme A reductase inhibitors (statins). The degree to which statins lower LDL-C varies based on the statin and the dose utilized. ${ }^{7,8}$ Current treatment guidelines suggest statin dosing consists of starting an initial dose and then titrating the dose in 6 weeks if the goal LDL-C is not obtained. ${ }^{2}$ The largest percentage of statin-induced LDL-C reduction is seen with suggested standard doses. An approximate $6 \%$ additional

submit your manuscript $\mid$ www.dovepress.con 
reduction is achieved each time the dose is doubled, which may allow a patient to achieve their ultimate goal LDL. ${ }^{4,8}$ Dose titration in patients not meeting goal depends on proper follow-up by the patient and practitioners. Surveys of lipidlowering therapy have suggested a significant percentage of patients are not properly managed. The EUROASPIRE II trial conducted from 1999 to 2000 revealed that of the patients needing lipid-lowering therapy ( $91.7 \%$ on statins) only $49 \%$ achieved their cholesterol goal. ${ }^{9}$ More recent surveys in other European countries have also demonstrated a significant portion of patients are not reaching goal. The CEPHUS survey revealed $58.5 \%$ of patients met the goal LDL-C, with $82.5 \%$ of the patients taking statins. ${ }^{10}$ High-risk patients needing to achieve a goal LDL-C of $<100 \mathrm{mg} / \mathrm{dL}$ may pose a problem if their initial LDL-C is significantly elevated. A survey of high-risk patients in a London-based practice showed $38.8 \%$ of patients on a statin reached goal LDL. ${ }^{11}$ Although it should be noted the goal LDL was $<2.0 \mathrm{mmol} / \mathrm{L}[77 \mathrm{mg} / \mathrm{dL}]$ based on the Joint British Societies' guidelines. ${ }^{11,12}$

Concerns about failing to appropriately titrate statins to goal have led to proposals of utilizing higher doses of statins as initial therapy. ${ }^{7}$ Data have shown that utilizing higher initial doses of atorvastatin allows more patients to reach their goal LDL-C without compromising safety. ${ }^{7}$ Other data have revealed that high dose atorvastatin $80 \mathrm{mg}$ /day has morbidity and mortality benefits vs pravastatin $40 \mathrm{mg} /$ day. ${ }^{13}$ A metaanalysis further showed that greater LDL-C lowering was associated with a lower number of cardiovascular events. ${ }^{14}$

Based on these data and the concern for patients not meeting goal LDL-C, it seems prudent to be more aggressive with initial statin dosing and select the initial starting statin dose based on the degree of LDL-C lowering required in each individual patient. Recently several studies have been conducted that utilize dosing algorithms to select the starting dose of atorvastatin. Atorvastatin has been shown to reduce LDL-C levels by $39 \%$ to $60 \%$ depending on the dose, which ranges from 10 to $80 \mathrm{mg}$ daily. ${ }^{15}$ These algorithms select the starting dose based on the patients' baseline LDL and/or CHD risk. This paper reviews these studies and provides discussion on the potential utility of such protocols in clinical practice. The first group of studies evaluates a range of high-risk and lowrisk patients, whereas the second group of studies specifically focuses on the high-risk diabetes population.

\section{Data sources}

A literature search was conducted using the terms lipidlowering medications, individualized dosing, algorithmbased dosing of statins, simvastatin, pravastatin, lovastatin, rosuvastatin, atorvastatin, and fluvastatin. MEDLINE, BIOSIS, EBSCOhost, and OVID databases were primary search sites from 2000 to August 2009. All English-based articles and abstracts obtained from the literature searches were reviewed. Additional information was obtained from references cited in the articles.

\section{Clinical evidence}

The initial study evaluating use of treatment algorithms with statins was the Atorvastatin Goal Achievement Across Risk Levels (ATGOAL) trial. ${ }^{16}$ The baseline characteristics and study design of the ATGOAL trial, as well as the other studies reviewed, are summarized in Table 1. ATGOAL was an 8-week study with a primary endpoint of determining the percentage of patients who reached the LDL-C target with starting doses of atorvastatin based on the baseline LDL-C and $\mathrm{CHD}$ risk category. All lipid-lowering medications were discontinued 8 weeks prior to the study. Baseline lipid profiles were obtained after the washout period. Patients were given atorvastatin (dose range 10 to $80 \mathrm{mg}$ /day) based on the LDL-C and risk categories (Table 2). A single dose titration at 4 weeks was available for patients who did not achieve their goal. At 8 weeks, 84.8\% (1031/1216) of patients attained their LDL-C target. At 4 weeks, the percentage of patients achieving the LDL-C target was 84.2\% (1049/1246). When analyzing the risk categories at 8 weeks, the attainment of goal was $92.9 \%(299 / 322)$ in the low risk group as compared to $84 \%(199 / 237)$ in the medium risk group and $81.1 \%(533 / 657)$ in the high risk group (Table 3$)$. Of the patients completing the study 156 were eligible for a dose titration at week 4; however only 110 of these patients actually had their dose increased with the remainder staying on the original dose per physician discretion. The secondary outcomes are listed in Table 4. A total of 225 patients had an adverse event and 52 (4\%) discontinued atorvastatin due to the adverse event. The discontinuation rates for possible, probable or definitely related adverse events were $0.6 \%$, $1.6 \%$ and $5.1 \%$ in the low-risk, medium-risk and highrisk groups, respectively. Less than $1 \%$ had an aspartate aminotransferase (AST) and/or alanine aminotransferase (ALT) elevation greater than 3 times upper limits of normal and there were no documented cases of creatine phosphokinase (CPK) elevation greater than 10 times upper limits of normal.

Two trials were designed using the same methodology but studied patients in different geographical areas. ${ }^{17,18}$ The Achieve Cholesterol Targets Fast with Atorvastatin Stratified Titration (ACTFAST)-1 study was conducted in Canada and 
Table I Clinical trials: study design and patient demographics ${ }^{|6-2|}$

\begin{tabular}{|c|c|c|c|c|c|c|}
\hline & ATGOAL ${ }^{16}$ & ACTFAST- $I^{17}$ & ACTFAST-2 ${ }^{18}$ & Ducobu et al ${ }^{19}$ & $\begin{array}{l}\text { Atorvastatin } \\
\text { Study Group in } \\
\text { Korea }^{20}\end{array}$ & $\begin{array}{l}\text { Ferrer-Garcia } \\
\text { et } \mathrm{al}^{2 !}\end{array}$ \\
\hline Study design & $\begin{array}{l}\text { Multicenter, } \\
\text { open-label, } \\
\text { single-step } \\
\text { titration }\end{array}$ & $\begin{array}{l}\text { Multicenter } \\
\text { prospective, } \\
\text { open-label, single } \\
\text { dose titration }\end{array}$ & $\begin{array}{l}\text { Multicenter, } \\
\text { prospective, open- } \\
\text { label, single dose } \\
\text { titration }\end{array}$ & $\begin{array}{l}\text { Multicenter, } \\
\text { prospective, } \\
\text { open-label, single } \\
\text { dose titration }\end{array}$ & $\begin{array}{l}\text { Multicenter, } \\
\text { prospective, } \\
\text { open-label, single } \\
\text { dose titration in } \\
\text { type } 2 \text { diabetes }\end{array}$ & $\begin{array}{l}\text { Prospective, no dose } \\
\text { titration, type } 2 \\
\text { diabetes }\end{array}$ \\
\hline Study duration & 8 weeks & 12 weeks & 12 weeks & 12 weeks & 8 weeks & 24 weeks \\
\hline Inclusion criteria & $\begin{array}{l}\text { Men or non- } \\
\text { pregnant women } \\
\text { between of } \\
\text { I8-80 years, } \\
\text { baseline LDL-C } \\
5.6 \mathrm{mmol} / \mathrm{L} \\
(\leq 220 \mathrm{mg} / \mathrm{dL}) \text {, } \\
\mathrm{TG} \leq 600 \mathrm{mg} / \mathrm{dL} \text {, } \\
\text { and capable of } \\
\text { maintaining life- } \\
\text { style and dietary } \\
\text { modifications }\end{array}$ & $\begin{array}{l}\text { Men or women at } \\
\text { least I8 years of } \\
\text { age with diagnosed } \\
\text { hyperlipidemia and } \\
\text { a LDL-C } \\
>2.6 \mathrm{mmo} / \mathrm{L} \\
\text { ( } 100 \mathrm{mg} / \mathrm{dL}) \text { along } \\
\text { with a screening } \\
\mathrm{LDL}-\mathrm{C} \\
\leq 5.7 \mathrm{mmol} / \mathrm{L} \\
(220 \mathrm{mg} / \mathrm{dL}) \text {, } \\
\text { TG level } \\
\text { of } \leq 6.8 \mathrm{mmol} / \mathrm{L} \\
\text { (600 mg/dL) and } \\
\text { were considered } \\
\text { high risk based on } \\
\text { history } \mathrm{CHD} \text {, CHD } \\
\text { equivalent, or } \\
\text { estimated I0-year } \\
\text { CHD risk }>20 \%\end{array}$ & $\begin{array}{l}\text { Men or women at } \\
\text { least I } 8 \text { years of } \\
\text { age with diagnosed } \\
\text { hyperlipidemia and } \\
\text { a LDL-C } \\
>2.6 \mathrm{mmo} / \mathrm{L} \\
\text { ( } 100 \mathrm{mg} / \mathrm{dL}) \text { along } \\
\text { with a screening } \\
\text { LDL-C } \\
\leq 5.7 \mathrm{mmol} / \mathrm{L} \\
(220 \mathrm{mg} / \mathrm{dL}) \text {, } \\
\text { TG level } \\
\text { of } \leq 6.8 \mathrm{mmol} / \mathrm{L} \\
\text { (600 mg/dL) and } \\
\text { were considered } \\
\text { high risk based on } \\
\text { history CHD, CHD } \\
\text { equivalent, or } \\
\text { estimated I0-year } \\
\text { CHD risk }>20 \%\end{array}$ & $\begin{array}{l}\text { LDL-C of } \\
3.0-6.1 \mathrm{mmol} / \mathrm{L} \\
(\mathrm{I} 15-235 \mathrm{mg} / \mathrm{dL}) \\
\text { after } 3 \text { months } \\
\text { of lipid-lowering } \\
\text { diet, TG level } \\
<400 \mathrm{mg} / \mathrm{dL} \text {, ages } \\
30-80 \text { years, and } \\
\text { were high } \mathrm{CHD} \\
\text { risk }\end{array}$ & $\begin{array}{l}\text { Men or women of } \\
18-80 \text { years with } \\
\text { hyperlipidemic } \\
\text { type } 2 \text { diabetes, } \\
\text { LDL-C } \\
\geq 130 \mathrm{mg} / \mathrm{dL} \text { or } \\
\text { glycated hemo- } \\
\text { globin } \leq 10 \% \text { and } \\
\text { TG } \leq 400 \mathrm{mg} / \mathrm{dL} \\
\text { at baseline }\end{array}$ & $\begin{array}{l}\text { Patients were at least } \\
\text { I8 years old, had } \\
\text { a glycated hemo- } \\
\text { globin of } \leq 10 \% \text {, } \\
\text { TG } \leq 6.8 \mathrm{mmol} / \mathrm{L} \\
(600 \mathrm{mg} / \mathrm{dL}) \text { and had } \\
\text { a baseline } \mathrm{LDL}-\mathrm{C} \\
\text { of }>2.6 \mathrm{mmol} / \mathrm{L} \\
(100 \mathrm{mg} / \mathrm{dL}) \text { despite } \\
6 \text { to } 12 \text { weeks of } \\
\text { dietary treatment }\end{array}$ \\
\hline Mean age (years) & $\begin{array}{l}55.1 \text { low-risk } \\
58.8 \text { medium-risk } \\
61.6 \text { high-risk }\end{array}$ & 63 & 61.2 & 62.1 & 58.4 & 61.1 \\
\hline \multicolumn{7}{|l|}{ Gender (\%) } \\
\hline Male & 58 & 68 & 61 & 70.2 & 28.9 & 59.9 \\
\hline Female & 42 & 32 & 39 & 29.8 & 71.1 & 40.1 \\
\hline Smokers & NR & $21 \%$ & $22.7 \%$ & $23.3 \%$ & NR & $29.7 \%$ \\
\hline Diabetes & $\begin{array}{l}44 \% \text { in the high- } \\
\text { risk group only }\end{array}$ & $39 \%$ & $32.7 \%$ & $34.4 \%$ & $100 \%$ & $100 \%$ \\
\hline History of CHD & $\begin{array}{l}54 \% \text { in the high- } \\
\text { risk group only }\end{array}$ & $61 \%$ & $67 \%$ & $61.9 \%$ & NR & NR \\
\hline $\begin{array}{l}\text { Mean baseline } \\
\text { LDL-C mmol/L } \\
(\mathrm{mg} / \mathrm{dL})\end{array}$ & $\begin{array}{l}4.8(187) \text { low-risk } \\
4.6(176) \\
\text { medium-risk } \\
4 . I(160) \text { high-risk }\end{array}$ & $\begin{array}{l}3.9(15 I) \text { in } \\
\text { statin-free group } \\
3.5(135) \text { in the } \\
\text { statin-treated } \\
\text { group }\end{array}$ & $\begin{array}{l}4 . I(159) \text { in } \\
\text { statin-free group } \\
3.8 \text { (I47) in } \\
\text { statin-treated } \\
\text { group }\end{array}$ & $4.1(158)$ & $160.3 \pm 22.4$ & $4.10 \pm 0.75$ \\
\hline
\end{tabular}

Abbreviations: NR, not reported; LDL-C, low-density lipoprotein cholesterol; TG, triglycerides; CHD, coronary heart disease.

Western Europe, while the ACTFAST-2 study was in northern and eastern Europe. ${ }^{17,18}$ The primary outcome was to assess achievement of LDL-C goal $(<2.6 \mathrm{mmol} / \mathrm{L}[<100 \mathrm{mg} / \mathrm{dL}])$, in high-risk patients, with starting doses of atorvastatin (dose range 10 to $80 \mathrm{mg} /$ day) based on the initial LDL-C baseline value with or without a single dose titration at 6 weeks. At 6 and 12 weeks, the secondary outcomes evaluated were the percentage of patients reaching a total cholesterol/high density lipoprotein-cholesterol (TC/HDL-C) ratio $<4$ and mean percent change in TC, LDL-C, HDL-C, TC/HDL-C ratio, non-HDL-C, triglycerides (TG), and apolipoproteinB (apo-B). Safety of atorvastatin was also monitored. The individuals agreed to follow a diet plan. Exclusion criteria was use of a nonstatin lipid-lowering medication in the last 
Table 2 Clinical trials: initial dosing protocols of atorvastatin ${ }^{16-21}$

\begin{tabular}{|c|c|c|c|c|}
\hline \multirow{3}{*}{$\begin{array}{l}\text { Baseline } \\
\text { LDL-C mmol/L } \\
(\mathrm{mg} / \mathrm{dL})\end{array}$} & \multicolumn{4}{|l|}{ ATGOAL study ${ }^{16}$} \\
\hline & \multicolumn{2}{|l|}{ Low-risk category } & \multirow{2}{*}{$\begin{array}{l}\text { Medium-risk } \\
\text { category } \\
\geq 2 \text { risk factors with } \\
10 \text {-year CHD risk } \\
10 \%-20 \%\end{array}$} & \multirow{2}{*}{$\begin{array}{l}\text { High-risk category } \\
\text { CHD, CHD equivalent, } \\
\geq 2 \text { risk factors with } \\
10 \text {-year CHD risk }>20 \%\end{array}$} \\
\hline & $\leq \mathrm{I}$ CHD risk factor & $\begin{array}{l}\geq 2 \text { risk factors } \\
\text { with } 10 \text {-year CHD } \\
\text { risk }<10 \%\end{array}$ & & \\
\hline $2.6-3.3(100-129)$ & NA & NA & NA & $10 \mathrm{mg}$ \\
\hline $3.4-3.6(130-139)$ & NA & NA & $10 \mathrm{mg}$ & $10 \mathrm{mg}$ \\
\hline $3.6-3.9(140-149)$ & NA & NA & $10 \mathrm{mg}$ & $10 \mathrm{mg}$ \\
\hline $3.9-4.1(150-159)$ & NA & NA & $10 \mathrm{mg}$ & $20 \mathrm{mg}$ \\
\hline $4.1-4.4(160-169)$ & $10 \mathrm{mg}$ & $10 \mathrm{mg}$ & $10 \mathrm{mg}$ & $40 \mathrm{mg}$ \\
\hline $4.4-4.6(170-179)$ & $10 \mathrm{mg}$ & $10 \mathrm{mg}$ & $10 \mathrm{mg}$ & $80 \mathrm{mg}$ \\
\hline $4.7-4.9(180-189)$ & $10 \mathrm{mg}$ & $10 \mathrm{mg}$ & $20 \mathrm{mg}$ & $80 \mathrm{mg}$ \\
\hline $4.9-5.7(190-220)$ & $10 \mathrm{mg}$ & $20 \mathrm{mg}$ & $20 \mathrm{mg}$ & $80 \mathrm{mg}$ \\
\hline \multirow[t]{2}{*}{ Target LDL-C } & $\begin{array}{l}<4.1 \mathrm{mmol} / \mathrm{L} \\
(<160 \mathrm{mg} / \mathrm{dL})\end{array}$ & $\begin{array}{l}<3.4 \mathrm{mmol} / \mathrm{L} \\
(<130 \mathrm{mg} / \mathrm{dL})\end{array}$ & $\begin{array}{l}<3.4 \mathrm{mmol} / \mathrm{L} \\
(<130 \mathrm{mg} / \mathrm{dL})\end{array}$ & $\begin{array}{l}<2.6 \mathrm{mmol} / \mathrm{L} \\
(<100 \mathrm{mg} / \mathrm{dL})\end{array}$ \\
\hline & \multicolumn{2}{|c|}{ ACTFAST I and 2 studies ${ }^{17,18}$} & & \\
\hline Baseline LDL-C mmol/L (mg/dL) & \multicolumn{2}{|l|}{ Statin-free group } & \multicolumn{2}{|l|}{ Statin-treated group } \\
\hline $2.6-3.8(100-149)$ & \multicolumn{2}{|l|}{$10 \mathrm{mg}$} & \multicolumn{2}{|l|}{$20 \mathrm{mg}$} \\
\hline $3.9-4.1(150-159)$ & \multicolumn{2}{|l|}{$20 \mathrm{mg}$} & \multicolumn{2}{|l|}{$40 \mathrm{mg}$} \\
\hline $4.2-4.4(160-169)$ & \multicolumn{2}{|l|}{$40 \mathrm{mg}$} & \multicolumn{2}{|l|}{$80 \mathrm{mg}$} \\
\hline \multirow[t]{2}{*}{$4.5-5.7(170-220)$} & \multicolumn{2}{|l|}{$80 \mathrm{mg}$} & \multicolumn{2}{|l|}{$80 \mathrm{mg}$} \\
\hline & \multicolumn{2}{|l|}{ Ducobu et al ${ }^{19}$} & & \\
\hline Baseline LDL-C mmol/L (mg/dL) & \multicolumn{2}{|l|}{ Statin-naïve patients } & \multicolumn{2}{|l|}{ Statin-treated patients } \\
\hline $3.0-4.2(115-164)$ & \multicolumn{2}{|l|}{$10 \mathrm{mg}$} & \multicolumn{2}{|l|}{$20 \mathrm{mg}$} \\
\hline $4.3-4.5(165-174)$ & \multicolumn{2}{|l|}{$20 \mathrm{mg}$} & \multicolumn{2}{|l|}{$40 \mathrm{mg}$} \\
\hline \multirow[t]{2}{*}{$4.5-6.1(175-235)$} & \multicolumn{2}{|l|}{$40 \mathrm{mg}$} & \multirow{2}{*}{\multicolumn{2}{|c|}{$40 \mathrm{mg}$}} \\
\hline & \multicolumn{2}{|c|}{ Atorvastatin study group in Korea ${ }^{20}$} & & \\
\hline \multicolumn{5}{|l|}{ Baseline LDL-C mmol/L (mg/dL) } \\
\hline $130-149$ & $10 \mathrm{mg}$ & & & \\
\hline $150-159$ & $20 \mathrm{mg}$ & & & \\
\hline$\geq 160$ & $40 \mathrm{mg}$ & & & \\
\hline & Ferrer-Garcia et $\mathrm{al}^{21}$ & & & \\
\hline Baseline LDL-C mmol/L (mg/dL) & Dose & & Target reduction in LDL & -C level (\%) \\
\hline $2.6-3.8(100-147)$ & $10 \mathrm{mg}$ & & 38 & \\
\hline $3.9-4.1(151-159)$ & $20 \mathrm{mg}$ & & 46 & \\
\hline $4.2-4.39(162-170)$ & $40 \mathrm{mg}$ & & 51 & \\
\hline$\geq 4.40(170)$ & $80 \mathrm{mg}$ & & 54 & \\
\hline
\end{tabular}

Abbreviations: CHD, coronary heart disease; NA, not-applicable; LDL-C, low-density lipoprotein cholesterol.

2 months, doses of $>40 \mathrm{mg} /$ day of any statin and current use of atorvastatin. Patients were divided into a statin-free group (no prior statins within the past 2 months) or a statintreated group (currently receiving a statin but not achieving LDL-C target goal). The dose assignment of atorvastatin is listed in Table 2.
The ACTFAST-1 study had 1345 patients in the statin-free group and 772 in the statin-treated group. ${ }^{17}$ At 12 weeks, $79.6 \%$ of statin-free patients achieved the LDL-C target as compared to $58.7 \%$ of statin-treated patients. Of those that achieved the target LDL-C goal $(n=1071), 90 \%$ in the statin-free group did so with their initial dose. Of the 
Table 3 Primary study outcomes ${ }^{16-21}$

\begin{tabular}{|c|c|c|c|c|c|}
\hline \multirow[t]{3}{*}{ Clinical trial } & \multirow[t]{3}{*}{ Treatment groups } & \multicolumn{4}{|c|}{ Proportion of subjects meeting goal $(\%)(95 \% \mathrm{Cl})$} \\
\hline & & \multicolumn{4}{|l|}{ LDL-C } \\
\hline & & 6 weeks & 8 weeks & 12 weeks & 24 weeks \\
\hline \multirow[t]{3}{*}{ ATGOAL ${ }^{16}$} & Low risk $(n=322)$ & NR & 92.9 & NR & NR \\
\hline & Medium risk $(n=237)$ & NR & 84.0 & NR & NR \\
\hline & High risk $(\mathrm{n}=657)$ & NR & 81.1 & NR & NR \\
\hline \multirow[t]{9}{*}{ ACTFAST- ${ }^{17}$} & Statin-free $(n=1345)$ & & & & \\
\hline & Atorvastatin $10 \mathrm{mg}$ & $84.3(81.5-87.0)$ & NR & $83.1(80.3-86.0)$ & NR \\
\hline & Atorvastatin $20 \mathrm{mg}$ & $83.4(78.0-88.8)$ & NR & $80.7(74.9-86.5)$ & NR \\
\hline & Atorvastatin $40 \mathrm{mg}$ & $88.9(83.9-93.9)$ & NR & $82.2(76.2-88.2)$ & NR \\
\hline & Atorvastatin $80 \mathrm{mg}$ & $79.9(75.3-84.4)$ & NR & $72.1(67.0-77.2)$ & NR \\
\hline & Statin-treated $(\mathrm{n}=772)$ & & & & \\
\hline & Atorvastatin $20 \mathrm{mg}$ & $55.1(51.0-59.2)$ & NR & $60.3(56.3-64.3)$ & NR \\
\hline & Atorvastatin $40 \mathrm{mg}$ & $55.4(44.1-66.7)$ & NR & $60.3(49.1-71.5)$ & NR \\
\hline & Atorvastatin $80 \mathrm{mg}$ & $58.1(48.7-67.5)$ & NR & $50.9(4 \mid .5-60.4)$ & NR \\
\hline \multirow[t]{9}{*}{ ACTFAST-2 ${ }^{18}$} & $\begin{array}{l}\text { Statin free }(n=34 \text { I at wk } 6 ; n=345 \\
\text { at week I2) }\end{array}$ & & & & \\
\hline & Atorvastatin $10 \mathrm{mg}$ & $77.8(71.0-84.6)$ & NR & $75.0(67.9-82.1)$ & NR \\
\hline & Atorvastatin $20 \mathrm{mg}$ & $82.0(71.4-92.7)$ & NR & $78.0(66.5-89.5)$ & NR \\
\hline & Atorvastatin $40 \mathrm{mg}$ & $86.5(71.2-95.5)$ & NR & $79.5(66.8-92.2)$ & NR \\
\hline & Atorvastatin $80 \mathrm{mg}$ & $69.1(60.5-77.7)$ & NR & $68.2(59.4-77.1)$ & NR \\
\hline & $\begin{array}{l}\text { Statin-treated }(n=249 \text { at week } 6 \\
n=253 \text { at week 12) }\end{array}$ & & & & \\
\hline & Atorvastatin $20 \mathrm{mg}$ & $52.4(44.3-60.5)$ & NR & $67.8(60.2-75.4)$ & NR \\
\hline & Atorvastatin $40 \mathrm{mg}$ & $60.7(42.6-78.8)$ & NR & 62.1 (44.4-79.7) & NR \\
\hline & Atorvastatin $80 \mathrm{mg}$ & $48.1(36.9-58.2)$ & NR & $46.8(35.6-57.9)$ & NR \\
\hline \multirow[t]{4}{*}{ Ducobu et al ${ }^{19}$} & Statin-naïve $(n=215)$ & & & & \\
\hline & Atorvastatin $10 \mathrm{mg}$ & NR & NR & NR & NR \\
\hline & Atorvastatin $20 \mathrm{mg}$ & NR & NR & 95.7 & NR \\
\hline & Atorvastatin $40 \mathrm{mg}$ & NR & NR & 95.6 & NR \\
\hline \multirow[t]{5}{*}{ Korea study ${ }^{20}$} & $(n=149)$ & & & & \\
\hline & Atorvastatin $10 \mathrm{mg}$ & NR & 87.5 & NR & NR \\
\hline & Atorvastatin $20 \mathrm{mg}$ & NR & 86.4 & NR & NR \\
\hline & Atorvastatin $40 \mathrm{mg}$ & NR & 93.9 & NR & NR \\
\hline & Atorvastatin $80 \mathrm{mg}$ & NR & 66.7 & NR & NR \\
\hline \multirow[t]{5}{*}{ Ferrer-Garcia et $\mathrm{a}^{21}$} & $(n=202)$ & & & & \\
\hline & Atorvastatin $10 \mathrm{mg}$ & NR & NR & NR & 75 \\
\hline & Atorvastatin $20 \mathrm{mg}$ & NR & NR & NR & 67 \\
\hline & Atorvastatin $40 \mathrm{mg}$ & NR & NR & NR & 51 \\
\hline & Atorvastatin $80 \mathrm{mg}$ & NR & NR & NR & 59 \\
\hline
\end{tabular}

Abbreviations: LDL-C, low-density lipoprotein cholesterol; NR, not reported.

435 patients reaching goal in the statin-treated group, the target LDL-C was achieved with atorvastatin at $20 \mathrm{mg}$ (72\%), $40 \mathrm{mg}(64 \%)$ and $80 \mathrm{mg}(96 \%)$. In the patients reaching goal in the statin-free group, titration was necessary with the doses of $10 \mathrm{mg}(\mathrm{n}=106), 20 \mathrm{mg}(\mathrm{n}=30)$ and $40 \mathrm{mg}$ $(\mathrm{n}=17)$ and target LDL-C was achieved in $58 \%, 67 \%$ and $69 \%$, respectively. Dose titration was needed in the statintreated group with target LDL-C achieved in $42 \%$ with the initial dose of $20 \mathrm{mg}(\mathrm{n}=260)$ and $52 \%$ with the initial dose of $40 \mathrm{mg}(\mathrm{n}=33)$. Of note, up to $20 \%$ of patients in each 
Table 4 Secondary study outcomes ${ }^{16-21}$

\begin{tabular}{|c|c|c|c|c|c|c|c|c|c|}
\hline \multirow[t]{2}{*}{ Clinical trial } & \multirow[t]{2}{*}{ Treatment groups } & \multicolumn{7}{|c|}{ Percentage mean reduction of lipid parameters from baseline } & \multirow{2}{*}{$\begin{array}{l}\begin{array}{l}\text { Proportion of } \\
\text { subjects }\end{array} \\
\text { TC/HDL-C } \\
\text { ratio target }<4\end{array}$} \\
\hline & & LDL-C & TC & TG & HDL-C & TC/HDL-C & Apo-B & Non-HDL-C & \\
\hline ATGOAL $^{16}$ & Low-risk group $(n=335)$ & -39.1 & -29.0 & -18.6 & -2.2 & NR & NR & -31.2 & NR \\
\hline 8-week & Medium-risk group $(n=249)$ & -36.8 & -28.7 & -20.9 & 1.7 & NR & NR & -31.4 & NR \\
\hline results & High-risk group $(\mathrm{n}=699)$ & -44.6 & -35.0 & -23.5 & -2.4 & NR & NR & -34.4 & NR \\
\hline \multirow{9}{*}{$\begin{array}{l}\text { ACTFAST- }\left.\right|^{17} \\
\text { I2-week results }\end{array}$} & Statin-free $(n=1345)$ & & & & & & & & \\
\hline & Atorvastatin $10 \mathrm{mg}$ & -34.8 & -23.9 & -13.7 & 3.1 & -25.4 & -31.5 & -32.1 & 83.1 \\
\hline & Atorvastatin $20 \mathrm{mg}$ & -43.8 & -31.6 & -22.7 & 1.4 & -32.0 & -39.4 & -41.0 & 85.9 \\
\hline & Atorvastatin $40 \mathrm{mg}$ & -49.8 & -37.2 & -26.5 & 1.6 & -37.4 & -44.8 & -47.1 & 86.9 \\
\hline & Atorvastatin $80 \mathrm{mg}$ & -52.7 & -39.7 & -5.2 & 0.6 & -39.1 & -46.8 & -48.7 & 79.1 \\
\hline & Statin-treated $(n=772)$ & & & & & & & & \\
\hline & Atorvastatin $20 \mathrm{mg}$ & -21.4 & -15.3 & -8.2 & 1.0 & -15.4 & -21.2 & -20.4 & 79.3 \\
\hline & Atorvastatin $40 \mathrm{mg}$ & -37.0 & -27.5 & -22.8 & 0.6 & -27.3 & -34.2 & -35.2 & 78.4 \\
\hline & Atorvastatin $80 \mathrm{mg}$ & -41.0 & -32.0 & -18.9 & -2.7 & -29.5 & -38.0 & -39.1 & 70.6 \\
\hline \multirow{9}{*}{$\begin{array}{l}\text { ACTFAST-2 }{ }^{18} \\
\text { I2-week results }\end{array}$} & Statin-free $(n=347)$ & & & & & & & & \\
\hline & Atorvastatin $10 \mathrm{mg}$ & -33.6 & -23.6 & -9.9 & 4.2 & -24.6 & -31.6 & -31.2 & 77.8 \\
\hline & Atorvastatin $20 \mathrm{mg}$ & -40.5 & -28.4 & -12.3 & 2.3 & -29.3 & -36.0 & -36.8 & 80.8 \\
\hline & Atorvastatin $40 \mathrm{mg}$ & -49.1 & -36.4 & -15.0 & -3.7 & -32.9 & -44.3 & -45.1 & 84.6 \\
\hline & Atorvastatin $80 \mathrm{mg}$ & -49.4 & -39.2 & -21.9 & -3.2 & -36.3 & -44.5 & -47.1 & 75.0 \\
\hline & Statin-treated $(n=253)$ & & & & & & & & \\
\hline & Atorvastatin $20 \mathrm{mg}$ & -24.7 & -17.4 & -3.8 & -2.7 & -13.3 & -22.5 & -21.9 & 71.2 \\
\hline & Atorvastatin $40 \mathrm{mg}$ & -36.6 & -27.0 & -19.9 & 4.1 & -28.3 & -33.1 & -34.8 & 82.8 \\
\hline & Atorvastatin $80 \mathrm{mg}$ & -40.2 & -30.8 & -19.5 & -1.4 & -29.1 & -36.3 & -37.7 & 66.7 \\
\hline $\begin{array}{l}\text { Ducobu et al } \\
\text { |2-week results }{ }^{19}\end{array}$ & $\begin{array}{l}\text { Statin-naïve }(\mathrm{n}=215) \\
\text { (Data NR based on dose) }\end{array}$ & -45.9 & -32.4 & NR & 0.04 & NR & NR & NR & NR \\
\hline \multirow{4}{*}{$\begin{array}{l}\text { Korea study } \\
8 \text {-week results }{ }^{20}\end{array}$} & Atorvastatin $10 \mathrm{mg}(\mathrm{n}=56)$ & -42.5 & -30.3 & -19.3 & 2.8 & NR & NR & -38.9 & NR \\
\hline & Atorvastatin $20 \mathrm{mg}(\mathrm{n}=22)$ & -52.9 & -37.5 & -32.6 & 4.0 & NR & NR & -49.4 & NR \\
\hline & Atorvastatin $40 \mathrm{mg}(\mathrm{n}=65)$ & -58.7 & -45.0 & -20.9 & -5.2 & NR & NR & -53.0 & NR \\
\hline & Atorvastatin $80 \mathrm{mg}(\mathrm{n}=6)$ & NR & NR & NR & NR & NR & NR & NR & NR \\
\hline \multicolumn{9}{|l|}{ Ferrer-Garcia } & NR \\
\hline \multirow[t]{3}{*}{ 24-week results } & Atorvastatin $20 \mathrm{mg}(\mathrm{n}=6 \mathrm{I})$ & -35.6 & -28.5 & -18.0 & -1.8 & NR & NR & -36.7 & NR \\
\hline & Atorvastatin $40 \mathrm{mg}(\mathrm{n}=35)$ & -35.5 & -29.8 & -26 & -0.2 & NR & NR & -38.2 & NR \\
\hline & Atorvastatin $80 \mathrm{mg}(\mathrm{n}=17)$ & -55.7 & -49.0 & -32.5 & -7.2 & NR & NR & -56.7 & NR \\
\hline
\end{tabular}

Abbreviations: NR, not reported; LDL-C, low-density lipoprotein cholesterol;TC, total cholesterol;TG, triglycerides; HDL-C, high-density lipoprotein cholesterol;TC/HDL-C, total cholesterol/low-density lipoprotein-cholesterol; Apo-B, apolipoprotein B; non-HDL-C, non-high-density lipoprotein cholesterol.

group that met criteria for dose titration did not actually receive an increased dose. Reasons why some patients did not have a dose titration were failure of investigator to follow protocols $(\mathrm{n}=23)$, patient not following directions $(\mathrm{n}=28)$ and adverse events $(\mathrm{n}=7)$. The primary and secondary efficacy outcomes are summarized in Tables 3 and 4.
The incidence of adverse events with all doses of atorvastatin was $12.1 \%$.Adverse events were asthenia (1.6\%), myalgia $(1.4 \%)$, constipation $(1.1 \%)$, dyspepsia $(1.1 \%)$, elevated AST/ALT $>3$ times upper limit, regardless of causality $(1.2 \%)$, and one case of elevated CPK $>10$ times the upper limit of normal. Of note, this patient did not report myalgia 
and had 2 falls 2 days prior due to a previous condition unrelated to statin therapy.

The ACTFAST-2 study results revealed $73.5 \%$ of patients in the statin-free group $(n=347)$ and $60.5 \%$ in the statin-treated group $(n=253)$ achieved the LDL-C target at 12 weeks..$^{18}$ At week 6, 391 patients had attained the primary outcome. The majority of subjects who reached goal achieved the target LDL-C by week 6 (96\%). Dose titration results were not reported because so few subjects met criteria for dose titration. The primary and secondary outcomes are summarized in Tables 3 and 4 . The most frequently reported adverse events were diarrhea $(0.5 \%)$, nausea $(0.5 \%)$, elevated AST/ALT (0.8\%) and myalgia (0.7\%). Twelve patients discontinued therapy.

The primary endpoint of the 12-week study by Ducobu et al was to determine the proportion of patients achieving their LDL-C goal with starting doses of atorvastatin (10 to $40 \mathrm{mg}$ /day) based on LDL-C levels. ${ }^{19}$ A single dose titration was allowed at week 6 by doubling the dose of atorvastatin if the goal LDL-C was not obtained. Secondary endpoints were mean percentage change in TC, LDL-C, HDL-C, and TG at weeks 6 and 12 along with proportion concomitantly reaching LDL-C and TC targets at week 12. Other secondary endpoints assessed were the proportion of patients reaching goal LDL-C at 6 weeks along with different LDL-C strata achieving LDL-C control at 6 and 12 weeks, proportion of diabetes patients achieving LDL-C control at 12 weeks and C-reactive protein (CRP) at baseline and at weeks 6 and 12. All patients were counseled on the Therapeutic Lifestyle Changes diet.' Medication-related exclusion criteria was use of nonstatin lipid-lowering medications (fibrates, resins, or acipimox) or atorvastatin during the last two months and higher maintenance doses of other statins such as $>40 \mathrm{mg}$ /day of simvastatin, fluvastatin or pravastatin. Patients were divided into two treatment groups; statin-naïve $(\mathrm{n}=215)$ and previously treated with a statin $(n=11)$. Due to the low overall number of patients in the previous statin treatment arm, the results in those subjects were not reported. Dosing of atorvastatin is listed in Table 2. In the statin-naïve group, 95.4\% (95\% CI 91.4\% to 97.9\%) reached their LDL-C goal at 6 weeks. Dose titration was required in $4.6 \%$ of patients. At 12 weeks, $96.4 \%$ (95\% CI $92.7 \%$ to $98.5 \%$ ) of the statinnaïve group reached the goal. Response rates did not vary based on the different starting dose subgroups. A secondary endpoint reported, with the statin-naïve group, was a mean standard deviation change in CRP of $-1.7(9.3) \mathrm{mg} / \mathrm{L}$ and $-1.4(9.1) \mathrm{mg} / \mathrm{L}$ at weeks 6 and 12, respectively. The mean percentage standard deviation change in the CRP was
$5.2(156.1)$ and 29.4 (253.8) at weeks 6 and 12. At 12 weeks, $97.1 \%$ of diabetes patients reached the LDL-C goal as compared to $95.6 \%$ of the nondiabetes patients. Overall $32.8 \%$ of patients reported an adverse event with headache, abdominal pain, diarrhea, and upper respiratory infection being the most commonly reported, occurring in $2.2 \%$ of patients. Although 3.4\% of patients withdrew from the study due to an adverse event, no serious adverse events were related to atorvastatin treatment.

\section{Clinical evidence in type 2 diabetes patients}

The Atorvastatin Study Group in Korea evaluated the flexible dosing of atorvastatin (dose range 10 to $40 \mathrm{mg} /$ day) based on the LDL-C in type 2 diabetes patients. ${ }^{20}$ The primary outcome was the percentage of patients meeting the goal LDL-C of $100 \mathrm{mg} / \mathrm{dL}$ following 8 weeks of therapy. Additional measurements were the percentage change over 8 weeks in HDL-C, TG, TC, non-HDL, ratio of LDL to HDL and non lipid-lowering effects such as flow-mediated endotheliumdependent dilation (FMD), flow-mediated endothelium independent dilation (EID) and plasminogen activator inhibitor type 1 (PAI-1). A 4-week washout period was done with any lipid-lowering agent prior to enrollment. Baseline lipid parameters and glycated hemoglobin were obtained. Medicationrelated exclusion criteria were previous use of niacin or fibrates. Continuation of the patient's diet and exercise plan was recommended during the study. The atorvastatin dosing protocol is listed in Table 2. At the end of 4 weeks, a dose titration could occur if the target LDL-C of $100 \mathrm{mg} / \mathrm{dL}$ was not met. Of the 209 enrolled patients, 149 completed the study. At 4 weeks, the percentage of patients reaching LDL-C goal was $90.3 \%, 88.9 \%$ and $91.3 \%$ when receiving $10 \mathrm{mg}, 20 \mathrm{mg}$ and $40 \mathrm{mg}$, respectively. At 8 weeks, the overall percentage of patients attaining the goal was $89.3 \%$ (95\% CI $84.3 \%$ to $94.2 \%$, Chi-square test $P=0.1722$ ). Fourteen patients $(9.4 \%)$ had a dose titration at 4 weeks. A dose-dependent statistically significant decrease occurred with LDL-C, TG and non-HDL-C $(P<0.0001)$. The pre- and post-treatment values for FMD improved $(P=0.0001)$ but the EID and PAI-1 did not reach statistical significance. The initial 209 patients were analyzed for safety of atorvastatin. Adverse events were abdominal pain (2.9\%), increased ALT (2.4\%), dizziness (1.9\%), headache/dyspepsia (1.4\%), and increased CK (1.4\%). Ten patients withdrew from the study due to adverse events, but no events were reported to be serious.

Ferrer-Garcia et al studied the dose assignment of atorvastatin $(10-80 \mathrm{mg} /$ day $)$ to the baseline LDL-C in 
statin-naïve type 2 diabetes patients. ${ }^{21}$ The primary efficacy outcome, at 24 weeks, was the percent of patients achieving the LDL-C target of less than $2.6 \mathrm{mmol} / \mathrm{L}(100 \mathrm{mg} / \mathrm{dL})$ without a dose titration. The mean percent change in $\mathrm{TC}$, LDL-C, HDL-C, non-HDL-C, and TG were assessed. All patients were instructed on diet. The dosage assignment is listed in Table 2. The overall proportion achieving the target was $66.5 \%(125 / 188)$ with an overall mean LDL-C reduction of $35 \%(P<0.001)$. Results based on atrovastatin dose are listed in Table 3 . The percent of change was statistically significant $(P<0.05)$ for TC $(-32.2 \%)$, HDL-C $(-3 \%)$, TG $(-22.2 \%)$ and non-HDL-C $(-39.7 \%)$ (see Table 4$)$. The adverse events that led to 2 patients withdrawing from the study were elevated liver enzymes ( $80 \mathrm{mg}$ group) and slight muscular pain (20 mg group).

\section{Discussion}

The clinical outcome benefits of using statins in patients with elevated cholesterol, with significant risk for coronary artery disease, or with known coronary artery disease have been well documented over the years by numerous clinical trials. Despite these known beneficial effects, it often takes a significant period of time to reach the desired cholesterol lowering goal or the goal is never reached at all. The studies described in this review looked at alternative, aggressive dosing schemes to initiate statin therapy to determine if the cholesterol-lowering goals can be achieved and if they can be achieved in a shorter time frame. The proposed theory is that achieving the LDL-C cholesterol goal in a shorter period of time may have a significant impact on long-term outcomes.

In the studies reviewed, various dosing approaches were utilized. In the ATGOAL trial, the initial atorvastatin dose was based on a baseline LDL-C measurement and cardiovascular risk categories combined. ${ }^{15,16}$ This dosing approach, which allowed 1 dose titration at 4 weeks, led to $84.8 \%$ of patients reaching their LDL-C goal at the end of the 8-week trial. The adverse event rate in this trial was relatively low, with an overall atorvastatin discontinuation rate of $4 \%$ due to adverse events. The ATGOAL trial demonstrated a high achievement of the LDL-C goal in a relativity short period of time which was well tolerated.

The ACTFAST-1 and -2 studies utilized a dosing regimen in which the initial atorvastatin dose was based on a baseline LDL-C measurement alone. ${ }^{17,18}$ A onetime dosage titration was allowed at 6 weeks during the 12-week trials if a patient had not reached their LDL-C goal. The treatment groups were divided into statin-free and statin-treated. In the ACTFAST-1 trial, the percent of patients achieving their LDL-C goal was higher in the statin-free group, $79.6 \%$, compared to the statin-treated patients, $58.7 \% .{ }^{17}$ Interestingly, $90 \%$ of the patients achieving their LDL-C goal in the statin-free group did so with their initial atorvastatin dose. This suggests that if a patient is going to respond well in achieving their LDL-C goal, an initial aggressive dose will likely result in this goal being reached. For those who have been previously on statin therapy and not achieved their LDL-C goal, in most cases, a dose titration will not always be adequate to assist them in achieving their LDL-C goal. The overall incidence of adverse events due to atorvastatin was $12.1 \%$, with myalgias and significantly elevated liver enzymes occurring in $1 \%$ to $2 \%$ of patients. Only 1 case of elevated CPK was reported, demonstrating that this dosing approach was relatively well tolerated.

The ACTFAST-2 trial results were similar to those seen in the ACTFAST-1 study. ${ }^{18}$ In the statin-free treatment group, $73.5 \%$ of patients achieved their LDL-C goal at 12 weeks, compared to $60.5 \%$ of patients achieving their LDL-C goal in the statin-treated group. Similar to the ACTFAST-1 study, $96 \%$ of the subjects who reached their LDL-C goal did so in the first 6 weeks of the 12-week trial. This again suggests that, if a patient is going to respond to statin therapy and reach the desired goal, this response will typically occur early on in therapy, if the initial dose is aggressive. Atorvastatin was well tolerated in this trial, with elevated liver enzymes and myalgias reported in less than $1 \%$ of subjects.

Similar to the trials just mentioned, the Ducobu study utilized an initial LDL-C measurement to determine an initial starting dose for atorvastatin. ${ }^{19}$ In addition, a one-time dosage titration was allowed midway through (at 6 weeks) of the study. Patients were categorized as statin-naïve and previously treated with a statin in the analysis, with only the statin-naïve group being reported in the study results. In the statin-naïve patient group, 95.4\% achieved their LDL-C treatment goal at 6 weeks. At 12 weeks, the percentage of statin-naïve patients achieving their LDL-C goal only increased to $96.4 \%$. Of note, the LDL-C treatment goal in this trial was less than $115 \mathrm{mg} / \mathrm{dL}$, which is higher than the current recommendations. These results again demonstrated that if patients with elevated LDL-C are being treated with aggressive doses of atorvastatin, the response to achieving the LDL-C treatment goal occurs relatively soon with the initial dose. Dosage titration in those not achieving their LDL-C with initial aggressive dosing is not likely to result in their achieving that LDL-C goal. 
The Atorvastatin Study Group in Korea assessed a sliding scale dosing approach based on initial LDL-C measurements in patients with type 2 diabetes mellitus. ${ }^{20}$ This study allowed 1 dosage titration midway through the study at 4 weeks. At the end of the trial, $89.3 \%$ of patients achieved their LDLC treatment goal. Only $9.4 \%$ of the patients in this study had dosage titration at 4 weeks of the study. In addition to evaluating the LDL-C treatment goal, the investigators evaluated pre- and post-values of FMD, EID, and PAI-1. Of these three measurements, only the post-FMD demonstrated an improvement over the pre-FMD measurement. The clinical significance of these three measurements and how they affect long-term clinical outcomes remain to be determined. From a safety standpoint, atorvastatin was well tolerated, with increases in ALT and CK reported in a small percentage of patients. Similar to the other studies, very few study subjects required a dosage titration, supporting the theory that this initial aggressive dosing strategy results in a majority of patients achieving the LDL-C goal with the initial dose.

The last study reviewed looked at a sliding scale dosage initiation based on a baseline LDL-C measurement in statinnaïve patients with type 2 diabetes mellitus. ${ }^{21}$ As noted in the trial description, dosage titration was not allowed in this trial. At the conclusion of this trial at 24 weeks, only $66.5 \%$ of the patients achieved their LDL-C treatment goal. The adverse event rate was very low with only 3 patients dropping out due to atorvastatin adverse events. This trial is not consistent with the results seen in the previous trials, in that fewer patients in this trial achieved their LDL-C treatment goal with the initial statin dosage regimen. It is difficult to determine if this difference is due to the study population or relative differences in the aggressiveness of the dosage regimens.

When comparing these trials, several difficulties were encountered. The initial dosage of atorvastatin differed based on the initial baseline LDL-C measurement, which makes head-to-head comparisons of these trials and their results complex. An additional difficulty is that two of these studies included only type 2 diabetes mellitus patients, which may be an unfair comparison to the other studies that did not included a solely diabetes mellitus population. The ATGOAL study was the only trial that included low and high risk patient populations. ${ }^{16}$ This trial also demonstrated a good rate of achievement in reaching the LDL-C treatment goal. Therefore, this dosing scheme would seem to be appropriate to implement into general clinical practice.
Collectively, the studies that were identified looking at initial dosing of statins in relationship to baseline LDL-C measurements demonstrated that a significant percentage of patients achieved their LDL-C goal during the duration of the study ${ }^{16-21}$ In addition, it is noteworthy that a majority of patients enrolled in these trials reached their LDL-C treatment goal with the initial dosage of atorvastatin. Patients who had higher baseline LDL-C levels, which are typically the most difficult to get to goal, were initially started on a higher dose of atorvastatin. This demonstrates that if a patient is going to achieve their LDL-C treatment goal, the response with initial dosing will be relatively quick, within 4 to 6 weeks. The percentage of patients meeting their LDL-C treatment goal after dosage titration was relatively small; therefore for patients not achieving the LDL-C treatment goal with this initial dosing strategy, an alternative pharmacologic combination or approach should be considered. The anticipated reductions in LDL-C levels that have been demonstrated in clinical trials are $38 \%, 46 \%, 51 \%$, and $54 \%$ reductions with $10 \mathrm{mg}, 20 \mathrm{mg}, 40 \mathrm{mg}$, and $80 \mathrm{mg}$ of atorvastatin, respectively. ${ }^{8}$

In addition to the primary goal of these trials, several of the trials evaluated secondary goals. ${ }^{16-21}$ Total cholesterol, TG, HDL-C, TC/HDL-C ratio, Apo-B, and non-HDL-C were utilized as secondary goals in these trials. Reductions in TC, TG, TC/HDL-C ratio, Apo-B, and non-HDL-C were observed in the trials assessing these outcomes. The effect in these studies of these dosing schemes on HDL-C was mixed.

One of the major limitations of the studies was that they were relatively short, ranging from 8 to 24 weeks. ${ }^{16-21}$ Since these trials were short, long-term outcomes such as reduced coronary events, mortality and other long-term outcome measures could not be assessed. Therefore, these studies were limited to using LDL-C lowering and other cholesterol profile markers as their major outcomes to determine if these dosing approaches were indeed effective in getting more people to goal in a shorter time. Based on the studies reviewed, it is evident that a larger percentage of patients achieved their LDL-C treatment goal in a time compared to traditional initiation and dosage titration of statin therapy. However, it remains to be seen whether or not this more aggressive approach of initiating statin therapy has any additional impact on long-term clinical outcomes.

A potential safety concern with this approach to the initiation of statin therapy is the possibility of a higher incidence of significant adverse effects. In the studies reviewed, the rate of adverse effects was relatively low and not higher 
than expected with traditional dosing of starting at a low dose and slowly titrating the dose up until the treatment goal is achieved. Choosing a more aggressive starting dose of a statin does not appear to cause a significantly higher rate of adverse reactions.

An additional limitation was that all of the studies identified and reviewed for initial aggressive dosing used only atorvastatin. It may not be appropriate to assume that this aggressive initial dosing will be as safe and efficacious with other statins. Studies assessing aggressive initial dosing of other statins should be conducted instead of trying to extrapolate these data to other drugs in this class.

Although the main focus of this review is on the statin therapy and dosing algorithm, it is important to remember the importance of diet therapy in patients with hyperlipidemia and coronary heart disease. As noted in the review of these trials, appropriate diet therapy was utilized, and clinicians should incorporate an appropriate diet as a part of the treatment approach.

It is difficult to take these studies as a whole and incorporate into practice an approach to initiating statin therapy. The main reasons this is difficult are that these trials did not utilize the same criteria and approach for determining the initial statin dose, and that some of the trials included patients who were already being treated with a statin.

The ATGOAL trial utilized a relatively complex approach to initiating statin therapy compared to the other studies that were identified and reviewed. In addition to utilizing the baseline LDL-C measurement, subjects were risk stratified based on their CHD risk, and then the initial statin dose was determined taking both of these factors into account. It could be argued that this approach is too complex in practice for the general clinical setting. However, this approach would likely be very useful in a specialized setting in which initiation of statin therapy was the major focus of the clinical practice, for example, a specialized lipid clinic.

Of the trials identified and reviewed, the dosing initiation algorithm that appeared to be the most user friendly for general practitioners as well as effective in achieving the LDL-C goal was that utilized in the ACTFAST-1 and -2 trials. ${ }^{17,18}$ Specifically, the "statin-free" treatment algorithm could be utilized and incorporated into most clinical settings and practices. This algorithm demonstrated achievement of the LDL-C goal in approximately $70 \%$ to $80 \%$ of the subjects by the end of the 12-week trial. In addition, this dosing approach was well tolerated, with minimal adverse effects reported.

\section{Conclusion}

Cardiovascular disease remains the leading cause of death in the world and has a significant impact on healthcare systems. Historically, the utilization of statins in the cardiovascular disease population has demonstrated a significant impact on clinical outcomes, specifically reduced mortality and reduced progression of cardiovascular disease and cardiovascular disease complications. Despite this evidence, many patients with cardiovascular disease either do not receive statin therapy, or are on suboptimal doses, as the medications are not uptitrated to achieve the treatment goals. The clinical trials reviewed assessed the efficacy and safety of using an initial dosing strategy determined by baseline LDL-C measurements to achieve treatment goals quicker. The studies demonstrated that some of the dosing strategies worked very well in reaching cholesterol treatment goals and were also well tolerated. The question that remains unanswered is what impact does achieving treatment goals sooner have on long-term clinical outcomes. Initial dosing of statin therapy with an algorithm utilizing a baseline LDL-C measurement appears to be a safe and effective option for starting a patient on statin therapy.

\section{Acknowledgments/disclosures}

We would like to acknowledge the administrative assistance of Barbara Papik, Medical Librarian Avera Sacred Heart Hospital Medical Library, Yankton, South Dakota, USA in searching the literature for this manuscript.

The authors report no financial interest or other conflicts of interest in this work.

\section{References}

1. World Health Organization. Cardiovascular disease fact sheet 2007. URL: http://www.who.int/mediacentre/factsheets/fs317/en/index.html. Accessed Sept 23, 2009.

2. Expert Panel on Detection, Evaluation, and Treatment of High Blood Cholesterol in Adults. Executive Summary of the Third Report of the National Cholesterol Education Program (NCEP) Expert Panel on Detection, Evaluation and Treatment of High Blood Cholesterol in Adults (Adult Treatment Panel III). JAMA. 2001;285:2486-2497.

3. De Backer G, Ambrosioni E, Borch-Johnsen K, et al. European guidelines on cardiovascular disease prevention in clinical practice [Third Joint Task Force of European and other Societies on Cardiovascular Disease Prevention in Clinical Practice]. Eur Heart J. 2003;24: $1601-1610$

4. Grundy SM, Cleeman JI, Merz CN, et al. Implications of Recent Clinical Trials for the National Cholesterol Education Program Adult Treatment Panel III Guidelines. Circulation. 2004;110:227-239.

5. Smith Jr SC, Allen J, Blair SN, et al. AHA/ACC Guidelines for Secondary Prevention for Patients With Coronary and Other Atherosclerotic Vascular Disease: 2006 Update. J Am Coll Cardiol. 2006;47: 2130-2139.

6. Executive Summary: Standards of Medical Care in Diabetes - 2009. Diabetes Care. 2009;32 Suppl 1:s6-s12. 
7. Jones PH, McKenney JM, Karalis DG, Downey J. Comparison of the efficacy and safety of atorvastatin initiated at different starting doses in patients with dyslipidemia. Am Heart J. 2005;149:e1-e8.

8. Jones P, Kafonek S, Laurora I, Hunninghake D. Comparative dose efficacy study of atorvastatin versus simvastatin, pravastatin, lovastatin, and fluvastatin in patients with hypercholesterolemia (The CURVES Study). Am J Cardiol. 1998;81:582-587.

9. EUROASPIRE I and II Group. Clinical reality of coronary prevention guidelines: a comparison of EUROASPIRE I and II in nine countries Lancet. 2001;357:995-1001.

10. Hermans MP, Van Mieghem W, Vandenhoven G, Vissers E. Centralized Pan-European Survey on the Undertreatment of Hypercholesterolaemia (CEPHEUS). Acta Cardiol. 2009;64:177-185.

11. Levine AP, Mikhailidis DP, Moross T, Benson K, Gor M. Achieving Vascular risk factor targets: a survey of a London general practice. Angiology. 2008;59:36-46.

12. British Cardiac Society, British Hypertension Society, Diabetes UK, HEART UK, Primary Care Cardiovascular Society, The Stroke Association. JBS 2: Joint British Societies' Guidelines on Prevention of Cardiovascular Disease in Clinical Practice. Heart. 2005;91 suppl v: $\mathrm{v} 1-\mathrm{v} 52$.

13. Cannon $\mathrm{CP}$, Braunwald $\mathrm{E}, \mathrm{McCabe} \mathrm{CH}$, et al. Intensive versus moderate lipid lowering with statins after acute coronary syndromes. $N$ Engl J Med. 2004;350:1495-1504.

14. Cholesterol Treatment Trialists' Collaborators. Efficacy and safety of cholesterol-lowering treatment: prospective meta-analysis of data from 90056 participants in 14 randomised trials of statins. Lancet. 2005;366:1267-78.
15. Lipitor (atrovastatin calcium) Prescribing Information. Pfizer Inc. June 2009. URL: http://www.pfizer.com/files/products/uspi_lipitor.pdf. Accessed Sept 24, 2009.

16. McKenney JM, Davidson MH, Saponaro J, et al. Use of a treatment algorithm to achieve NCEP ATP III goals with atorvastatin. J Cardiovasc Pharmacol. 2005;46:594-599.

17. Martineau P, Gaw A, de Teresa E, et al. Effect of individualizing starting doses of a statin according to baseline LDL-cholesterol levels on achieving cholesterol targets: The Achieve Cholesterol Targets Fast with Atorvastatin Stratified Titration (ACTFAST-1) study. Atherosclerosis. 2007:191:135-146.

18. Farsang C, Athyros V, Gaw A. A multicentre, open study to assess the effect of individualizing starting doses of atorvastatin according to baseline LDL-C levels on achieving cholesterol targets: the Achieve Cholesterol Targets Fast with Atorvastatin Stratified Titration (ACTFAST-2) study. Curr Med Res Opin. 2007;23:1945-1956.

19. Ducobu J, Claeys M, Commers K, et al. Efficacy of atorvastatin after LDL-cholesterol-based dose selection in high risk dyslipidaemic patients: results of the target dose study. Curr Med Res Opin. 2007;23:1821-1827.

20. Atorvastatin Study Group in Korea. Flexible initial dosing of atorvastatin based upon initial lo-density lipoprotein cholesterol levels in type 2 diabetic patients. Korean J Intern Med. 2008;23:22-29.

21. Ferrer-Garcia JC, Snachez-Ballester E, Albalat-Galera R, et al. Efficacy of atorvastatin for achieving cholesterol targets after LDL-cholesterol based dose selection in patients with type 2 diabetes. $J$ Cardiovasc Pharmacol Ther. 2008;13:183-188.
Risk Management and Healthcare Policy

\section{Publish your work in this journal}

Risk Management and Healthcare Policy is an international, peerreviewed, open access journal focusing on all aspects of public health, policy, and preventative measures to promote good health and improve morbidity and mortality in the population. The journal welcomes submitted papers covering original research, basic science, clinical \& epidemio-

\section{Dovepress}

logical studies, reviews and evaluations, guidelines, expert opinion and commentary, case reports and extended reports. The manuscript management system is completely online and includes a very quick and fair peerreview system, which is all easy to use. Visit http://www.dovepress.com/ testimonials.php to read real quotes from published authors. 